\title{
The Time Lags Effects of Innovation Input on Output in National Innovation Systems: The Case of China
}

\author{
Dan Wang, ${ }^{1,2}$ Xinli Zhao, ${ }^{1,3}$ and Zhenshan Zhang, \\ ${ }^{1}$ School of Management, Harbin Institute of Technology, Harbin 150001, China \\ ${ }^{2}$ Northeast Agricultural University, Harbin 150030, China \\ ${ }^{3}$ China Science and Technology Exchange Center, Beijing 100045, China \\ ${ }^{4}$ School of Economics and Management, Heilongjiang Institute of Science and Technology, Harbin 150022, China
}

Correspondence should be addressed to Xinli Zhao; zhaoxl@cstec.org.cn

Received 20 June 2016; Accepted 16 August 2016

Academic Editor: Ilija Vukotic

Copyright (c) 2016 Dan Wang et al. This is an open access article distributed under the Creative Commons Attribution License, which permits unrestricted use, distribution, and reproduction in any medium, provided the original work is properly cited.

\begin{abstract}
This paper investigates the time lags effects of innovation input on output in the national innovation systems (NIS). Firstly, we analyze the intrinsic properties of China's NIS based on the conceptual framework and the causal loop diagram. Secondly, we construct a time lags distribution calculation model and employ the main innovation input indicators to measure the specific characteristics of time lags effects of innovation input on output for China in the period 2000-2012. The results indicate that there are considerable time lags in the four major feedback loops, and the distribution of time lags is various according to the characteristics of innovation input and influencing factors in the internal transformation. The trends of time lags from R\&D personnel and industryacademia-research collaboration show steady growth, and the trends of time lags from R\&D expenditure and government's macrocontrol take inverted U-shaped pattern. Finally, we combine the estimation results of lags distribution calculation model with the analysis results of the causal loop diagram (including positive loops and negative loops) to provide some innovation policy suggestions. This study provides important implications for our understanding of the long-term complex lags effects of innovation input on output as well as for policy-makers designing and implementing the innovation strategies.
\end{abstract}

\section{Introduction}

The concept of the national innovation systems (NIS) emerged in the late 1980s [1] and further developed in the years that followed [2-4]. NIS is a crucial driver of economic growth and competitiveness [5] and enjoys widespread attention in both academic and policy-making contexts [6]. Although there is no single definition of NIS, a good synthetic summary of the prevailing definitions is given as follows: “... the system of interacting private and public firms (either large or small), universities and government agencies, aiming at the production of science and technology (S\&T) within national borders. Interaction among those units may be technical, commercial, legal, social and financial, in as much as the goal of the interaction is the development, protection, financing or regulation of new S\&T" [7].

Many studies have been carried out over the last two decades. These studies can be listed in three categories.
The first category focuses on the structure of NIS $[1,2,8]$. These studies identify and describe the main components of the system and investigate their mutual interactions as well as their relationships with the social and institutional environment in which the system is embedded [9]. The aims of these studies are to recognize the main determinants influencing the production, use, and dissemination of new technologies [10]. The studies of the second category concentrate on various functions of NIS. The functions are the activities that contribute to the goal of innovation systems (both positive and negative) [11], and they are often used in relation to particular institutions [12] or to the system as a whole $[2,13,14]$. The third category of studies is related with the effectiveness of NIS which mainly cover the efficiency evaluation of input-output system $[15,16]$ and international comparisons of innovation capability [17-19]. Much attention has so far been given to the efficiency evaluation of NIS, because this study helps both to identify the best innovation 
TABLE 1: National Science and Technology Conferences of China.

\begin{tabular}{|c|c|c|}
\hline Year & Name of conference & Theme \\
\hline March, 1978 & National Science Conference & $\begin{array}{l}\text { Deng Xiaoping reiterated the famous thesis of S\&T as a productive force and } \\
\text { scientists as workers. The conference adopted the National Compendium on } \\
\text { Scientific and Technological Development (1978-1985) (Draft). S\&T were } \\
\text { assigned a crucial role in China. }\end{array}$ \\
\hline May, 1995 & $\begin{array}{l}\text { National Science and Technology } \\
\text { Conference }\end{array}$ & $\begin{array}{l}\text { China began to carry out the development strategy of revitalizing the nation by } \\
\text { relying on science and education. Decision on accelerating S\&T progress } \\
\text { (CCCP) was emphasized. }\end{array}$ \\
\hline August, 1999 & $\begin{array}{l}\text { National Technology and } \\
\text { Innovation Conference }\end{array}$ & $\begin{array}{l}\text { The government issued the Decision on Strengthening Innovation, Developing } \\
\text { High Technology and Realizing Industrialization, called for the construction of } \\
\text { NIS, and clarified the task of promoting the translation of scientific and } \\
\text { technological achievements into practical productive forces. }\end{array}$ \\
\hline January, 2006 & $\begin{array}{l}\text { National Science and Technology } \\
\text { Conference }\end{array}$ & $\begin{array}{l}\text { The government brought forward the National Guideline on Medium- and } \\
\text { Long-Term Program for Science and Technology Development (2006-2020), } \\
\text { and the goal is to become an innovation-oriented country by } 2020 \text {. }\end{array}$ \\
\hline July, 2012 & $\begin{array}{l}\text { National Technology and } \\
\text { Innovation Conference }\end{array}$ & $\begin{array}{l}\text { Accelerate the construction of a diversified, multilevel, multichannel } \\
\text { technological investment and financing system. Continue to increase investment } \\
\text { in S\&T to achieve the goal of increasing R\&D intensity to } 2.5 \text { percent of GDP by } \\
2020 \text {. }\end{array}$ \\
\hline May, 2016 & $\begin{array}{l}\text { National Technology and } \\
\text { Innovation Conference }\end{array}$ & $\begin{array}{l}\text { Reinforce the foundation of S\&T; rank among the world's most advanced in the } \\
\text { important areas of S\&T; strengthen the strategic orientation; solve the S\&T } \\
\text { problems in innovation development; enhance the S\&T supply, service to the } \\
\text { main battlefield of economic and social development; deepen the reform } \\
\text { innovation; form S\&T management and operation mechanism full of vigour; } \\
\text { carry forward the spirit of innovation; foster the personnel in line with } \\
\text { requirements of innovation and development. }\end{array}$ \\
\hline
\end{tabular}

practitioners for benchmarking and to shed light on ways to improve efficiency by distinguishing weakness [16]. While a substantial amount of research has been devoted to the investigation of the innovation input-output ratio and the effect of public policy intervention on the innovation efficiency, the analysis of the dynamics of innovation input-output in NIS was neglected over time.

Some researchers [20-22] have found that the research process takes time and the current research and development (R\&D) may not have an effect on measured productivity until several years have elapsed. And the NIS comprises a network of interacting policies, institutions, and organizations [23] whose innovative performance depends not only on how the individual component part performs in isolation, but on the quality of interaction and cooperation between the various elements [24, 25], which is subject to dynamic processes [26]. Therefore, the transform process from innovation input to innovation output may be delayed because of the interaction and influence of various factors in NIS. The innovation input cannot generate innovation output and profits immediately or there is the multiple-period influence of one-time innovation input on output.

Because of the significance of the time lags in NIS and the lack of relevant research, this paper focuses on the time lags effects of innovation input on output in NIS. We construct a time lags distribution calculation model to investigate the structure and extent of time lags of major innovation inputs on output, and then we discuss the time lags effects regarding the national innovative factors in the long-run evolution of NIS from both quantitative and qualitative point of view.
The rest of the paper is as follows. Section 2 provides an overview of the study area: China's national innovation system. Section 3 is devoted to describing the methodology and presenting the data for the research study of time lags. The analysis results of time lags effects of innovation input on output for China are reported in Section 4. In Section 5, policy implications drawn from empirical results are discussed. Finally, Section 6 provides a brief summary and potential future research aspects.

\section{Overview of China's NIS}

China has experienced three decades of sustained and strong economic growth as its transitions from a centrally planned economy to a free market, and the associated reforms have necessitated changes in the field of S\&T. Since the early 1980s, China has promulgated a series of policies for promoting R\&D nationwide [27]. And the development process of China's NIS is reflected by the six important National Science and Technology Conferences (1978, 1995, 1999, 2006, 2012, and 2016) (see Table 1).

Notable progress has been made in the construction and the structural transformation of China's NIS. Enterprises have been becoming the center in both the funding structure and performing structure of S\&T expenditures on a state level; however, the central government remains the leading force in reforming its NIS with Chinese characteristics [28].

2.1. Conceptual Framework of China's NIS. Figure 1 shows the conceptual framework of China's NIS. The framework is put 


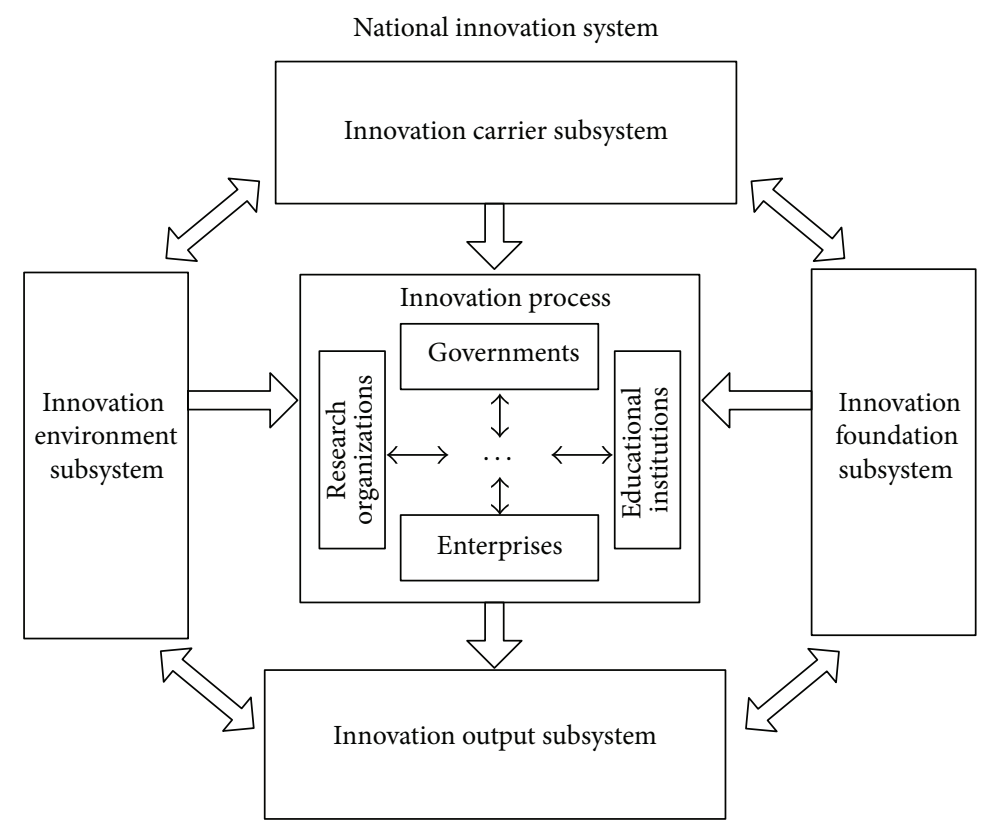

Figure 1: Conceptual framework of China's NIS.

forward based on the current situation of China and extensive references to the literatures, such as Porter's Diamond Model [29], FP\&S Model [30], and M\&J Model [31]. Our framework contains four subsystems: innovation foundation subsystem, innovation environment subsystem, innovation carrier subsystem, and innovation output subsystem.

2.1.1. Innovation Foundation Subsystem. Innovation foundation subsystem is the most basic element of China's NIS. It represents the level of national economic and social development as well as the input and contribution of the country to innovation development.

2.1.2. Innovation Environment Subsystem. Innovation environment subsystem is the important guarantee to the effective operation of China's NIS. Favorable innovation environment not only can effectively allocate the innovation resources but also foster a highly competitive innovation carrier. Innovation environment subsystem involves many elements, such as social environment, policy environment, business environment, and ecological sustainability.

2.1.3. Innovation Carrier Subsystem. Innovation carrier subsystem includes innovation human resources and R\&D expenditure. Innovation carriers flow among the various innovation entities. The role is responsible for linking each innovation entity.

2.1.4. Innovation Output Subsystem. Innovation outputs are the results of innovative activities. The quantity and quality of innovation outputs represent the development and implementation dynamics of innovation activities.

2.1.5. Internal Links between the Subsystems. Innovation foundation and innovation environment subsystems are the foundation and guarantee of innovation carrier and innovation output subsystem, whereas innovation output can also strengthen innovation foundation, improve innovation environment, and provide more resources for innovation by promoting economic development. The growth of innovative resources drives the dynamics of scientific, technological, and innovative output. In contrast, the growth of innovation output sustains further innovative investments over time, in turn.

2.2. Causal Loop Diagram of China's NIS. The literatures suggest system dynamic (SD) as a well-documented methodological approach for studying the dynamic behavior of innovation systems [32-34]. And a causal loop diagram is a map of system with all its constituent components and their interactions. A causal loop diagram represents the major feedback mechanisms. These mechanisms are either positive feedback or negative feedback loops. The positive sign (“+”) indicates a reinforcing effect, while the negative sign ("-") represents a balancing effect.

In order to reach a better understanding of what really takes place inside China's NIS, we developed a causal loop diagram of China's NIS (shown in Figure 2) based on conceptual framework. And there are four major feedback loops in the diagram.

2.2.1. Feedback Loop of R\&D Personnel. The first loop (Figure 3 ) shows that an increase of public expenditure devoted to education may lead to the improvement of the education level. In this way, increasing public expenditure on education may stimulate the production of human capital for scientific and technological research and then promote the production of innovation achievement.

2.2.2. Feedback Loop of R\&D Expenditure. The second loop (Figure 4) describes that the government fiscal policies and 


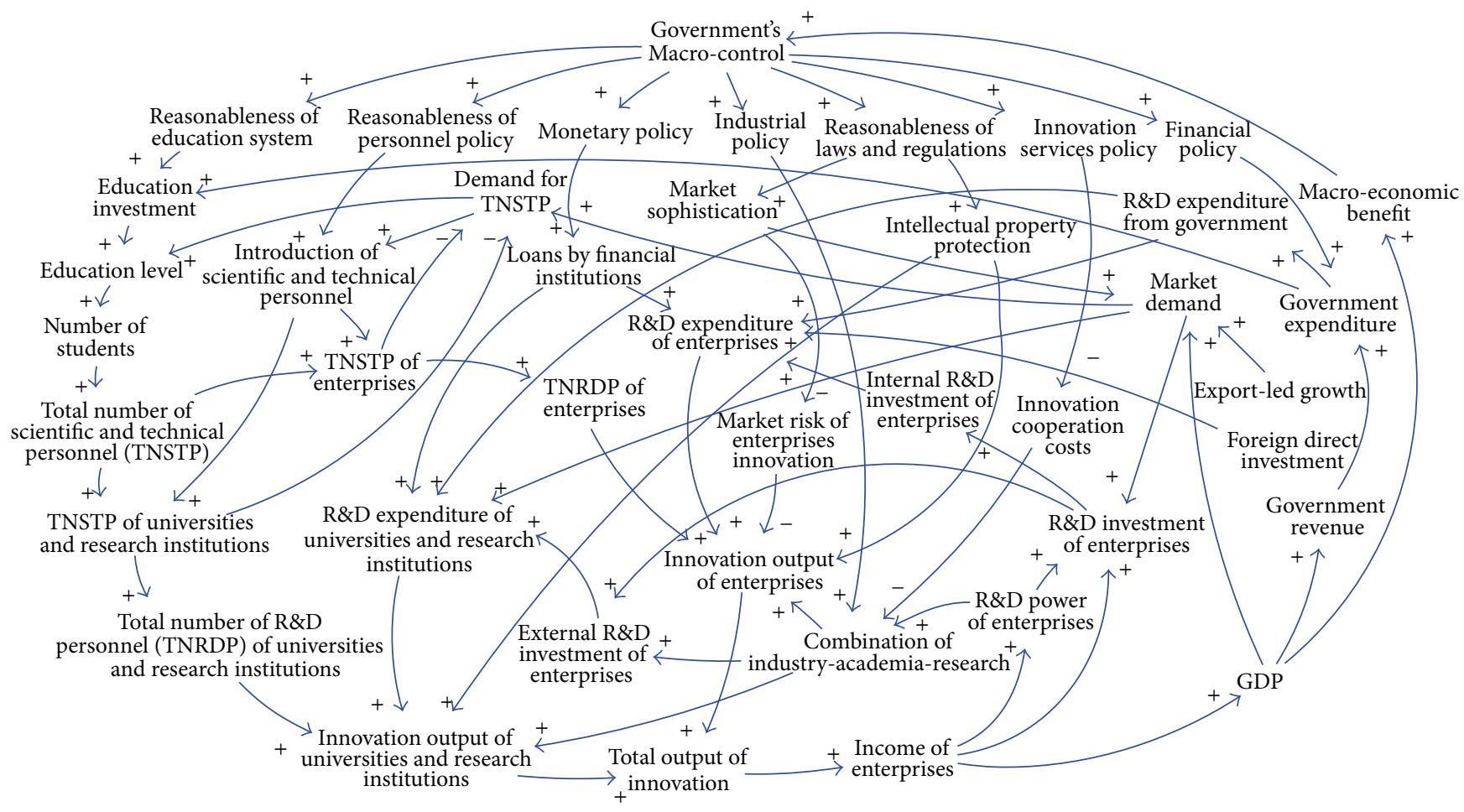

FIgURE 2: Causal loop diagram of China's NIS.

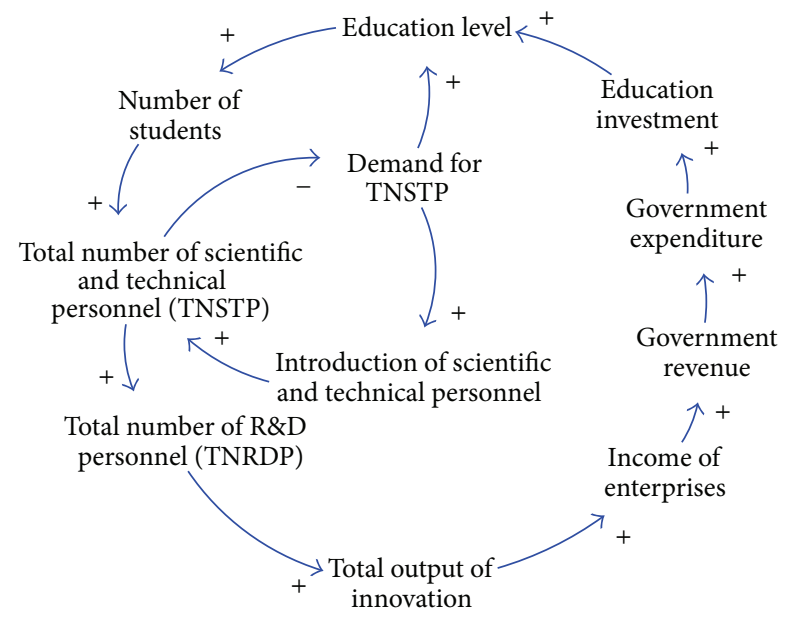

FIGURE 3: Feedback loop of R\&D personnel.

increasing $\mathrm{R} \& \mathrm{D}$ expenditure of enterprises for themselves and for research universities and research institutions effectively promote innovation outputs.

2.2.3. Feedback Loop of Government's Macro-Control. The third loop (Figure 5) depicts that the scientific and technological advances help drive economic and social development and then strengthen the government's macro-control. The reform of the S\&T management system will be accelerated, and the innovation quantity and innovation quality will be

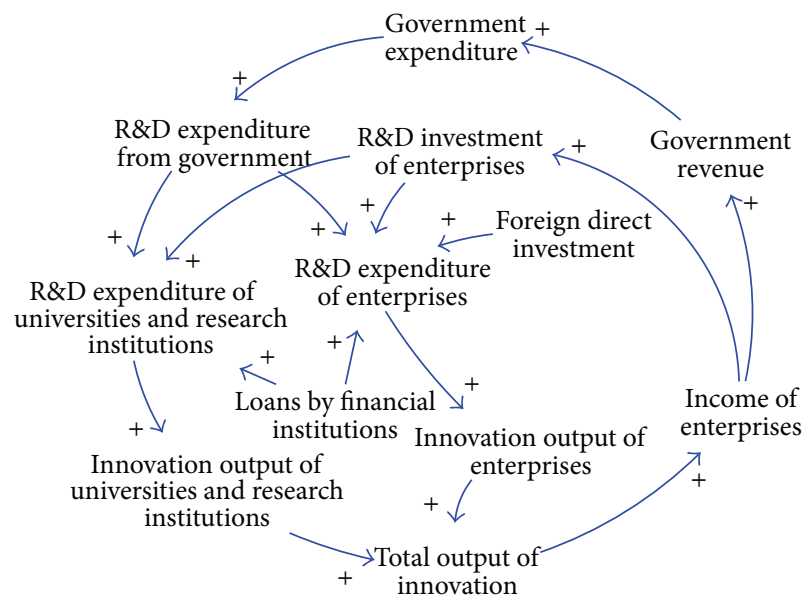

FIGURE 4: Feedback loop of R\&D expenditure.

enhanced in turn on the back of the government's macrocontrol policies and measures, such as fiscal policies, monetary policies, industrial policies, and the protection and use of intellectual property rights.

2.2.4. Feedback Loop of Industry-Academia-Research Collaboration. Most major technological advances and innovations originate from interactions between industry and the scientific community [35]. Many countries are actively encouraging industry-academia-research collaboration to improve innovation efficiency and therefore enhance wealth creation. 


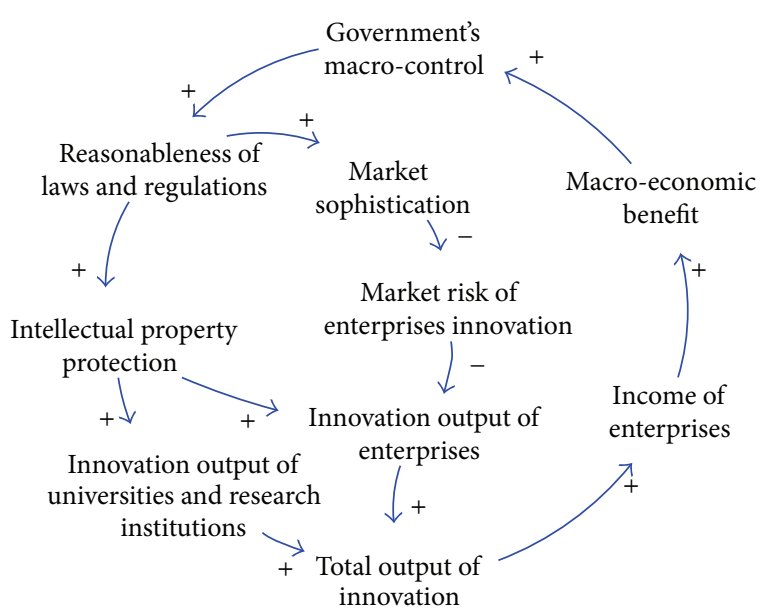

FIGURE 5: Feedback loop of government's macro-control.

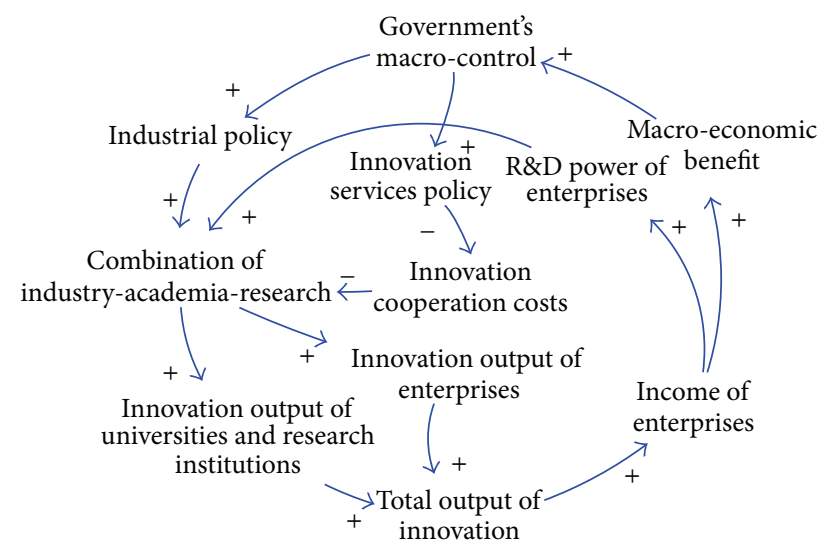

FIGURE 6: Feedback loop of industry-academia-research collaboration.

It can be seen from the fourth loop (Figure 6) that the collaboration helps promote research, development, and innovation.

China has become the world's second largest economy in the world today, with the gross domestic product (GDP) of 56.88 trillion yuan (9.3 1 trillion U.S. dollars) in 2013, according to the National Bureau of Statistics (NBS). Nevertheless, today China also faces the challenge of making the transition from sustained to sustainable growth from social, economical, ecological, and environmental points of view. Innovation has been identified as a main engine to fuel the next phase of growth, and China's "National Guideline on Medium- and Long-Term Program for Science and Technology Development (2006-2020)" reflects its determination to overcome growing problems through S\&T and to become a world leader in innovation. Therefore investigating the operation mechanism of China's NIS is useful for adjusting the development strategies of NIS and for enhancing S\&T capabilities.

\section{Methodology and Data}

To study the questions raised in the earlier discussion we implement a time lags distribution calculation model. Then key indicators and data in the time lags analysis are described.
3.1. Methodology. In this section, we construct a time lags distribution calculation model based on the grey system theory. Grey system theory, which is a mathematical method to deal with the dynamic system, was formulated by Deng [36]. The grey correlation analysis (GCA) is to determine whether the relationship among a series of data is close, based on the degree of similarity among the geometric shapes of the data series' curves. The closer the distance between the curves becomes, the greater the correlation among the relative data series is. Compared with traditional regression statistical methods, which require more data and time, GCA can determine the relationship between variables based on the input-output data, without assuming a concrete production function. There are many other advantages, such as no special requirement on the sample size and data distribution, a small amount of calculation, and ease of programming. The method has been applied in many fields [37, 38]. Measuring the time lags effects, GCA has been proven to be useful empirically [39, 40]. For example, Wang et al. [39] and Liu and Guo [40] applied GCA in an analysis of the lag effects of $\mathrm{R} \& \mathrm{D}$ expenditure on economic growth in China.

Accordingly, to cope with the multicollinearity of NIS, we applied GCA for estimating the time lags structure of the effect of innovation input on output [41]. The steps are as follows.

3.1.1. Sequence Determination. There are two kinds of lag sequences: reference sequence and comparative sequence. The reference sequence reflects the behavior features of the system. The data sequence consisting of factors which affect the behavior of system is called comparative sequence. The lag sequences are as follows:

$$
\begin{aligned}
& Y^{L}=\{i=L+1, L+2, \ldots, 17 \mid y(i)\}, \\
& X^{L}=\{i=1,2, \ldots, 17-L \mid x(i)\},
\end{aligned}
$$

where $L$ is the lag step length. The minimum amount of data in the GCA is 3. In order to ensure the basic condition of the model, we set $L \leq 17-3=14(L=0,1,2, \ldots, 14) . Y^{L}$ is the reference sequence, and $X^{L}$ is the comparative sequence.

3.1.2. Data Preprocessing. Data preprocessing should be performed before the calculation of the grey correlation coefficients. Data preprocessing converts the original sequence to a dimensionless sequence. The original sequence is normalized as follows:

$$
\begin{aligned}
& y^{L^{\prime}}(i)=\frac{y(i)}{y(L+1)}-1, \quad i=L+1, L+2, \ldots, 17, \\
& x^{L^{\prime}}(i)=\frac{x(i)}{x(1)}-1, \quad i=1,2, \ldots, 17-L,
\end{aligned}
$$

where $y^{L^{\prime}}(i)$ and $x^{L^{\prime}}(i)$ are the normalized element in the reference and comparative sequence, respectively.

3.1.3. Grey Relative Correlation Grade Calculation. The grey relative correlation grades in different lag steps are calculated. 
TABLE 2: Indicator, feedback loop, units of measure, and sources of data.

\begin{tabular}{lccc}
\hline Indicator & Feedback loop & Units of measure & Sources of data \\
\hline Researchers in R\&D (per million people) (RRD) & R\&D personnel & Headcounts $^{\text {. }}$ & WB $^{\mathrm{a}}$ \\
R\&D expenditure (\% of GDP) (RDE) & R\&D expenditure & $-2.5-2.5$ & $\mathrm{WB}^{\mathrm{a}}$ \\
Regulatory quality (RQ) & Government's macro-control & $1-7$ & $\mathrm{WB}^{\mathrm{a}}$ \\
University-industry research collaboration (UIRC) & Industry-academia-research collaboration & WEF-GCR $^{\mathrm{b}}$ \\
Patent applications, residents (PAR) & - & Total number $^{\mathrm{WB}^{\mathrm{a}}}$ \\
\hline
\end{tabular}

Notes:

${ }^{\mathrm{a}}$ WB: World Bank.

${ }^{b}$ WEF-GCR: World Economic Forum-Global Competitiveness Report.

The lag step of the maximum grey relative correlation grade, which is taken as the time difference of the reference sequence caused by the comparative sequence, is the final time lag of this comparative sequence.

Using (3), we define the following calculation model of grey relative correlation grade:

$$
\begin{aligned}
& \gamma_{X Y}^{L}=\frac{1+\left|S_{X}\right|+\left|S_{Y}\right|}{1+\left|S_{X}\right|+\left|S_{X}\right|+\left|S_{Y}-S_{X}\right|}, \\
& \left|S_{X}\right|=\left|\sum_{k=2}^{17-L} x^{L^{\prime}}(k)+\frac{1}{2} x^{L^{\prime}}(17-L)\right|, \\
& \left|S_{Y}\right|=\left|\sum_{k=L+1}^{17} y^{L^{\prime}}(k)+\frac{1}{2} y^{L^{\prime}}(17)\right|, \\
& \left|S_{Y}-S_{X}\right|=\mid \sum_{k=L+1}^{17} y^{L^{\prime}}(k)-\sum_{k=2}^{17-L} x^{L^{\prime}}(k) \\
& +\frac{1}{2}\left(y^{L^{\prime}}(17)-x^{L^{\prime}}(17-L)\right) \mid, \\
& \gamma_{X Y}^{L^{*}}=\max _{L=0}^{14} \gamma_{X Y}^{L},
\end{aligned}
$$

where $\gamma^{L}{ }_{X Y}$ is the grey relative correlation grade of $L ; \gamma^{L^{*}}{ }_{X Y}$ is the maximum grey relative correlation grade; $L^{*}$ is the lag step of the maximum grade; if $L^{*}=0$, the reference sequence and the comparative sequence are synchronized; otherwise, if $L^{*}>0$, we take the comparative sequence as the lag indicator of the reference sequence. $L^{*}$ is the final time lag of this indicator.

3.2. Data. Based on the analysis results in Section 2.2, the four major feedback loops describe the major feedback mechanisms of R\&D personnel, R\&D expenditure, government's macro-control, and industry-academia-research collaboration promoting innovation outputs. Accordingly, four input indicators representing the four feedback loops are considered: researchers in $R \& D$ (per million people) (RRD), R\&D expenditure (\% of GDP) (RDE), regulatory quality (RQ), and university-industry research collaboration (UIRC).

$\mathrm{RQ}$ is from the Worldwide Governance Indicators (WGI) which are a research dataset summarizing the views on the quality of governance provided by a large number of enterprises, citizens, and expert survey respondents in industrial and developing countries. It reflects perceptions of the ability of the government to formulate and implement sound policies and regulations that permit and promote private sector development. Estimate of governance ranges from approximately -2.5 (weak) to 2.5 (strong) governance performance [42].

UIRC is from the average answer to the survey question of the World Economic Forum: In your country, to what extent do business and universities collaborate on $\mathrm{R} \& \mathrm{D}$ ? $[1=$ do not collaborate at all; $7=$ collaborate extensively].

Since patents are often considered an important indicator of technological change and innovation [43-46], this paper will take the patent application as the variable for the innovation output indicator. Table 2 provides the indicators, the feedback loops which belong to, their units of measurement, and the sources of data. The detailed indicator values are given in Table 3. The empirical analysis accounts for annual time series data for China from 1996 to 2012.

\section{Results and Discussion}

The results presented in this section are based on the time lags distribution calculation model (see Section 3.1). Table 4 and Figures 7-10 provide the estimated lag structures and trends of the key innovation input indicators (RRD, RDE, RQ, and UIRC) on the innovation output indicator (PAR) over time. We will discuss them in greater detail combined with the four major feedback loops of China's NIS, in which both quantitative and qualitative research strategies can be used to complement each other.

Before the computation of time lags, we test all variables for unit roots. Augmented Dickey Fuller (ADF) [47] test which is one of the most popular tests for a unit root in a time series sample is applied to check the stationary of data. The tests are computed with automatic lag length selection relying on Schwarz information criterion (SIC) and with a maximum lag length of 3 . The results show that RRD, RDE, $\mathrm{RQ}$, and UIRC are stationary at first difference level and PAR is stationary at second difference level. All computations are performed with the help of EViews.

The estimation results of GCA are presented in Table 4.

4.1. Time Lags from R\&D Personnel. The results for RRD are shown in Table 4 (column (I)) and Figure 7. $\max _{L=0}^{14} \gamma_{X Y}^{L}=$ $\gamma^{14}{ }_{X Y}=0.55122$, and the maximum lag step $L^{*}=14$. The stable effects dominate during the period between the first year after start-up and the thirteenth year, suggesting a relatively 
TABLE 3: Indicator values for China in the period 2000-2012.

\begin{tabular}{|c|c|c|c|c|c|}
\hline \multirow{2}{*}{ Year } & \multicolumn{5}{|c|}{ Indicator } \\
\hline & RRD & $\mathrm{RDE}$ & RQ & UIRC & PAR \\
\hline 1996 & 439.13877 & 0.56828 & -0.13516 & 4.5 & 11628 \\
\hline 1997 & 468.32919 & 0.64473 & -0.20000 & 4.5 & 12672 \\
\hline 1998 & 383.72696 & 0.65297 & -0.26299 & 4.5 & 13751 \\
\hline 1999 & 417.23123 & 0.75705 & -0.30000 & 4.5 & 15626 \\
\hline 2000 & 542.83543 & 0.90276 & -0.32728 & 4.5 & 25346 \\
\hline 2001 & 576.69967 & 0.95069 & -0.43000 & 4.5 & 30038 \\
\hline 2002 & 625.73243 & 1.07003 & -0.53062 & 4.5 & 39806 \\
\hline 2003 & 661.72951 & 1.13356 & -0.33689 & 4.5 & 56769 \\
\hline 2004 & 706.83900 & 1.22989 & -0.27516 & 4.5 & 65786 \\
\hline 2005 & 848.67066 & 1.32476 & -0.13197 & 4.5 & 93485 \\
\hline 2006 & 922.79131 & 1.38830 & -0.18082 & 4.5 & 122318 \\
\hline 2007 & 1066.72756 & 1.39582 & -0.15001 & 4.5 & 153060 \\
\hline 2008 & 1185.95467 & 1.46986 & -0.13126 & 4.4 & 194579 \\
\hline 2009 & 852.77564 & 1.70198 & -0.20169 & 4.4 & 229096 \\
\hline 2010 & 890.44101 & 1.75899 & -0.21872 & 4.4 & 293066 \\
\hline 2011 & 963.20314 & 1.83617 & -0.20984 & 4.4 & 415829 \\
\hline 2012 & 1019.57213 & 1.98305 & -0.25833 & 4.4 & 535313 \\
\hline
\end{tabular}

Notes:

RRD represents researchers in $R \& D$ (per million people).

RDE represents R\&D expenditure (\% of GDP).

$\mathrm{RQ}$ represents regulatory quality.

UIRC represents university-industry research collaboration; data resource (2007-2012) is World Economic Forum, Executive Opinion Survey; missing data during 1996-2006 is assigned a value equal to $2007 ; 1=$ do not collaborate at all, and 7 = collaborate extensively.

PAR represents patent applications, residents.

TABLE 4: Results of the time lags distribution calculation model.

\begin{tabular}{ccccc}
\hline$L$ & (I) RRD & (II) RDE & (III) RQ & (IV) UIRC \\
\hline 0 & 0.50115 & 0.55205 & 0.53820 & 0.50122 \\
1 & 0.50126 & 0.55010 & 0.53900 & 0.50134 \\
2 & 0.50137 & 0.54800 & 0.54109 & 0.50147 \\
3 & 0.50157 & 0.54794 & 0.54493 & 0.50168 \\
4 & 0.50257 & 0.56953 & 0.57273 & 0.50289 \\
5 & 0.50309 & 0.57296 & 0.58915 & 0.50352 \\
6 & 0.50415 & 0.58745 & 0.62444 & 0.50490 \\
7 & 0.50607 & 0.61321 & 0.68574 & 0.50763 \\
8 & 0.50717 & 0.61102 & 0.73531 & 0.50925 \\
9 & 0.51059 & 0.64271 & 0.85774 & 0.51502 \\
10 & 0.51462 & 0.66711 & $0.99724^{*}$ & 0.52257 \\
11 & 0.51954 & 0.67747 & 0.98769 & 0.53270 \\
12 & 0.52757 & $0.70199^{*}$ & 0.96874 & 0.55053 \\
13 & 0.53516 & 0.67807 & 0.97928 & 0.56946 \\
14 & $0.55122^{*}$ & 0.69874 & 0.95005 & $0.61581^{*}$ \\
\hline
\end{tabular}

Notes:

RRD: researchers in R\&D (per million people); RDE: R\&D expenditure (\% of GDP); RQ: regulatory quality; UIRC: university-industry research collaboration.

The data marked with $*$ is assumed to be the maximum grey relative correlation grade which indicates the final time lag of this indicator.

long innovation accumulation period. The positive impact of $\mathrm{RRD}$ on PAR reaches peak around 14 years after entry.

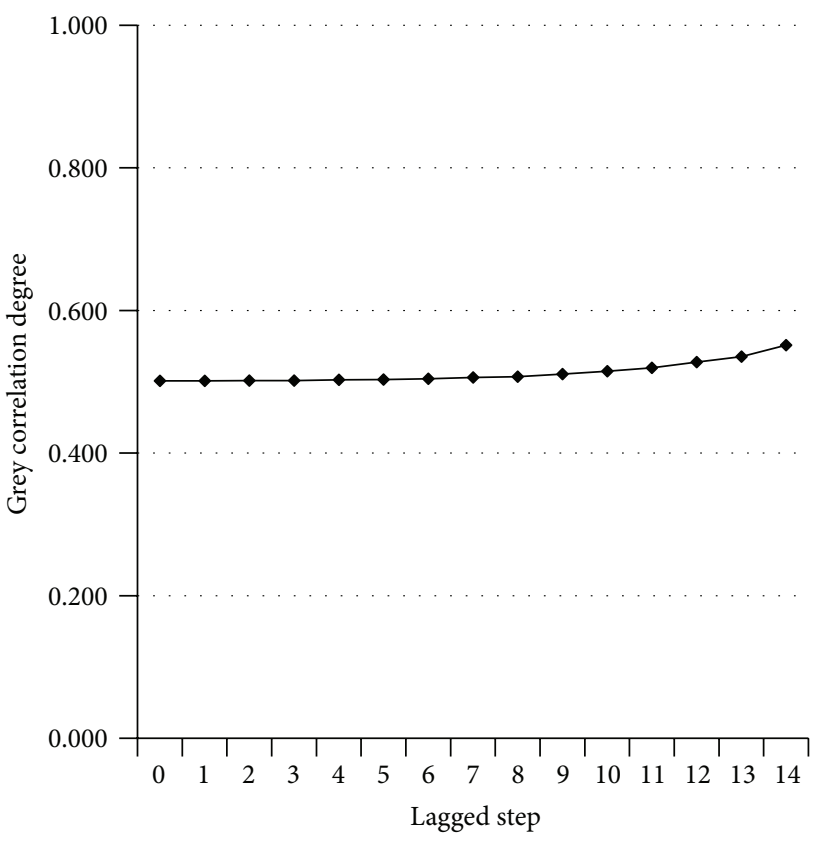

FIgURE 7: Time lags effects of RRD on PAR.

Promoting the education sector normally entails increasing public expenditure on education [48], as well as further integration of educational resources. Effective integration of educational resources is a long-term and systematic project. 


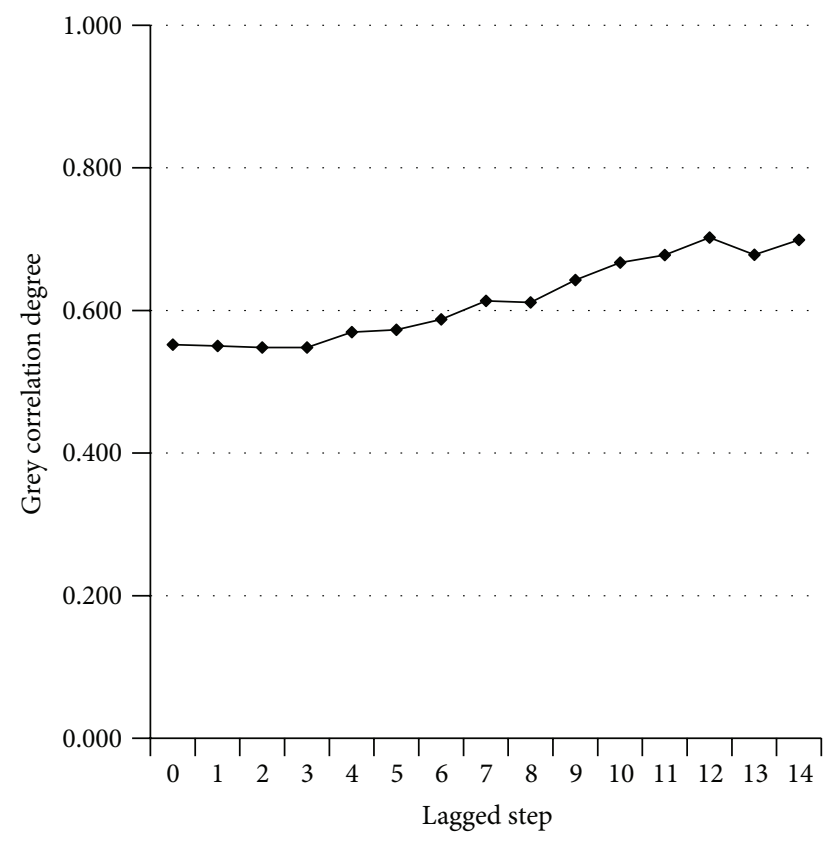

Figure 8: Time lags effects of RDE on PAR.

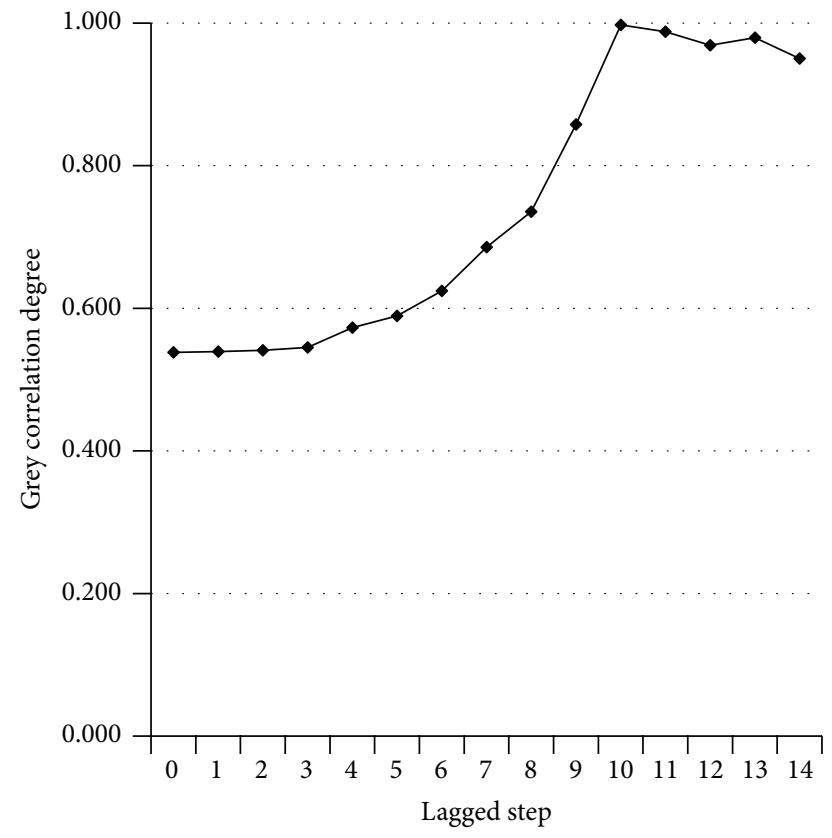

FIgURE 9: Time lags effects of RQ on PAR.

Personnel training process takes time and graduates may not contribute to innovation in short time. Researchers in R\&D need to undergo a process of germination, growth, and maturity. That is the time lag from the process of training R\&D personnel.

From the negative causal effect (in Figure 3) point of view, the growth of TNSTP may lead to reduction of the demand for TNSTP, decrease the number of personnel training and the personnel introduction, and then slow down the pace of innovation output.

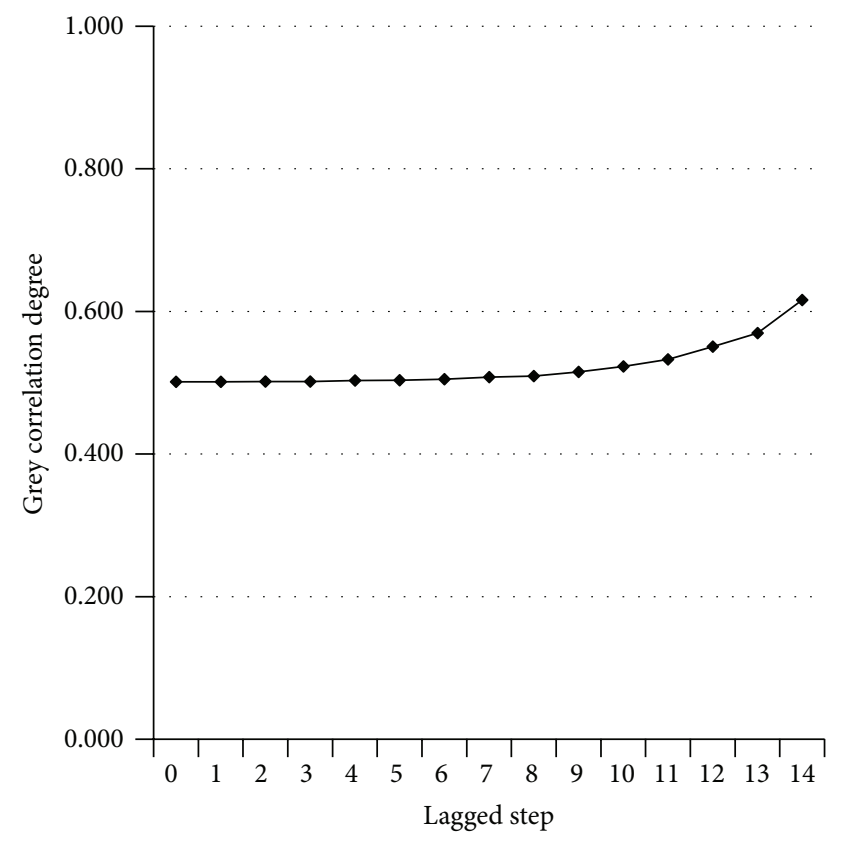

FIgURe 10: Time lags effects of UIRC on PAR.

4.2. Time Lags from R\&D Expenditure. For RDE, $\max _{L=0}^{14} \gamma_{X Y}^{L}=\gamma_{X Y}^{12}=0.70199$, and the maximum lag step $L^{*}=12$ (Table 4, column (II), and Figure 8). The peak of the positive impact of RDE on PAR is reached about 12 years after entry and then fades away.

The main role of $\mathrm{R} \& \mathrm{D}$ expenditure is to provide cash flow for the whole innovation process. $R \& D$ expenditure provides an important guarantee for the successful operation of the innovation process, and in the meantime, the innovation process influences circulation of $R \& D$ expenditure in turn. It can be said that the time lags from innovation process can cause a certain delay in the use of $\mathrm{R} \& \mathrm{D}$ expenditure. The time lags in the innovation process mainly come from two aspects. On the one hand, the innovation process, which integrates the existing technology, R\&D expenditure, personnel, and so forth into a holistic dynamic consideration, needs to go through a period of time. This period is called the normal time lags. On the other hand, whether or not such an innovation process can succeed is uncertain because there are a variety of risk factors, including decision-making risk, personnel risk, financial risk, technology risk, and industry risk. Any risks are likely to have a negative impact on the development process, to extend the innovation process, and even to ruin the entire research project. The delay caused by the risk factors is called the nonnormal time lags. It is the two aspects of delay that explain the time lags of the innovation process from input to output as well as the use of R\&D expenditure.

4.3. Time Lags from Government's Macro-Control. Table 4 (column (III)) and Figure 9 present the estimated lag structures of RQ, $\max _{L=0}^{14} \gamma_{X Y}^{L}=\gamma_{X Y}^{10}=0.99724$, and the maximum lag step $L^{*}=10$. According to the results, the 
magnitude of such effects over time takes an inverted Ushaped pattern with a peak for the start-up activity from ten years earlier, while no significant decrease is identified after the peak.

There are still the time lags in the process of government policy formulation, development, and implementation. The reason is twofold. Firstly, a fundamental role of the governments is the configuration of regulations and legislation via which a nation's innovative activity is influenced [29]. The formulation of government innovation policy, which takes a number of steps, may require a lot of time. Secondly, there may be considerable time lags involved when governments launch numerous innovation policies to improve the environment for innovation. The transformation needed in the lagging innovation environments is hampered by the limitations and disadvantages of conventional and traditional system of organization.

As can be seen from the negative causal effect in Figure 5, irrational government regulations may enhance the market risk of enterprises innovation. And the end result may be the slowdown of innovation output.

4.4. Time Lags from Industry-Academia-Research Collaboration. As shown in Table 4 (column (IV)) and Figure 10, for UIRC, $\max _{L=0}^{14} \gamma_{X Y}^{L}=\gamma_{X Y}^{14}=0.61581$, and the maximum lag step $L^{*}=14$. The positive effect of UIRC on PAR has steadily increased since the start-up activity, tending to peak around the fourteenth year. With the accumulation of data, UIRC will lead to more PAR in the longer run.

The analyses of the time lags for industry-academiaresearch collaboration are presented on the two aspects: process and factors (barriers). On the one hand, the process of industry-academia-research collaboration is a knowledge transfer process in a certain sense. Szulanski [49] conceptualized the phases of knowledge transfer using the milestones. Nonaka and Takeuchi [50] proposed the SECI (Socialization, Externalization, Combination, Internalization) model to present the spiraling knowledge processes of interaction between explicit knowledge and tacit knowledge. The knowledge transfer process of industry-academia-research collaboration is nonlinear paths of knowledge acquisition, knowledge sharing, and knowledge application by and among the various partners in the innovation process. In addition, prior to setting up a research collaboration, there is a "step by step" process of how to include a consultancy agreement [51]. In conclusion, the whole process of industry-academiaresearch collaboration may take a while or a long time. Thus, there may be a long delay at this stage. On the other hand, a variety of barriers and constraints may adversely affect industry-academia-research relationships and reduce the collaboration efficiency. Industry and universities might be well motivated to collaborate, but there are many barriers to such involvement and the considerable potential benefits are often not realized in practice [52]. Published literature suggests that the most significant barriers are in general related to differences or conflicts in the missions and objectives, institutional differences (different cultures and structures), different research interests of companies and universities, ineffective communication, restrictions in information dissemination due to confidentiality issues, and conflicts over intellectual property rights $[53,54]$.

As shown in Figure 6, the negative causal effect is that unreasonable innovation services policy may increase the costs of innovation collaboration, reduce the intensity of industry-academia-research cooperation, and thereby slow down the innovation output.

\section{Implications for Policy}

The time lags effects regarding the national innovative factors in the long-run evolution of China's NIS have been identified and analyzed. The analyses and discussions presented above suggest important implications for policy-makers to ensue.

5.1. Personnel Policy. The results shown in Figure 7 indicate that researchers need to go through the technical accumulation cycle of 14 years in order to maximize their usefulness to innovation output. How can the accumulation cycle be shortened? These are two important aspects to improve efficiency of input-output.

From the point of view of the positive causal effect: First, the basic problem is to increase the quality and quantity of $\mathrm{R} \& \mathrm{D}$ personnel by implementing higher educational reforms. Second, make the training mechanism of R\&D personnel better and strive to shorten the period from novice to expert. The training mechanism reform contains the following: (1) Develop strong quality standards and procedures for training the new R\&D personnel; (2) propose a personalized training system (including the training content and the training means) for different groups; (3) carry out training evaluation to achieve the maximum training effectiveness; (4) pay attention to the training of the organization culture and core values. Third, the direct introduction of foreign, highly skilled "talent" will play a significant role in shortening the technical accumulation cycle in China. Creating the appropriate working and living environments is an effective means of attracting and retaining foreign talent. And another means is to establish China as an education hub, attracting foreign talent that may remain in the country, bringing in foreign revenue, and helping to draw more multinational $\mathrm{R} \& \mathrm{D}$ companies to China.

When considering the negative causal effect shown in Figure 3, the government should balance the demand for TNSTP to achieve a balanced development of training and introduction of S\&T personnel.

5.2. R๘D Funding Policy. From Figure 8, the positive effect of RDE on PAR gradually increases within a 12 -year period that continues for a relatively long time. There is a close connection between R\&D process and efficiency of $R \& D$ funding utilization (see Section 4.2). Therefore, optimizing $\mathrm{R} \& \mathrm{D}$ process as well as improving $\mathrm{R} \& \mathrm{D}$ performance is an effective method of reducing the normal time lags, decreasing the nonnormal time lags, and then shortening the time lags of R\&D funding input on output. These methods include the following: (1) Eliminate the boundaries between departments in order to achieve the goal-oriented team without boundary; (2) build and optimize market-oriented R\&D process; 
(3) focus on risk management, including risk identification, risk analysis, risk planning, risk tracking, and risk response. In addition, increase the quantity of innovation input, at the same time, paying more attention to the sustainability of innovation input. A certain amount of innovation input may have no significant effect on innovative performance growth immediately. Safeguard the persistence of innovative investment, especially in the rising phase of the contribution rate of RDE on PAR.

5.3. Government Innovation Policy. The results (Figure 9) may be attributed to the relatively long time lags that are required for the national macro-control policies to become visible, the durability of public policy, and the enhancement of the market risk faced by enterprises innovation.

First, (1) improve the efficiency of formulation, development, and implementation of government innovation policy; (2) strengthen the macro-coordination of innovation policies and regulations across China and deal with the central-local government relations, internal relations of science departments, and science-nonscience department relations well to avoid repeated policy deployments. Second, get rid of the ideological obstacles and institutional barriers and dredge the transmission channel of innovation policy, for speeding up playing the effect of innovation policies and regulations. Third, play the continuing effect of policies and regulations on innovation output. Coordinate the relationship between policies and regulations for innovation and other types of policies and laws, seek common ground while reserving differences, and then explore the breadth and depth of the coordination. Furthermore, perfect the relevant laws and regulations for keeping up with the constant change of the objective conditions and legal environment. Finally, in order to accelerate innovation output, the government should make more reasonable innovation-related regulations, which help to improve the market sophistication and reduce the market risk of enterprises innovation.

5.4. Industry-Academia-Research Collaboration Policy. There is a 14-year maximum lag structure and contribution rate of UIRC on PAR varies at a slow speed (Figure 10), which indicates that the run-in period of collaboration persists longer.

In order to shorten the run-in period, we can implement the following strategies: Firstly, improve the efficiency of knowledge transfer from the knowledge acquisition, knowledge sharing, and knowledge application [49]; secondly, establish consulting agency [51], which provides highstandard consultancy services (e.g., consultancy agreement, technology transfer, intellectual property, and investment and financing decisions); thirdly, as shown in Figure 10, the gradual increasing effect of UIRC on PAR suggests that, after a period of run-in, both parties may easily boost their credibility, visibility, and reputation; in other words, they can work well with each other. Therefore, an option to help accelerate the development of business academia interactions is to plan more long-term value-added collaborations based on the existing collaborations. Strive to develop deeplevel relationship and invent the novel collaboration pattern models; finally, reduce the negative causal effect of unreasonable industry-academia-research collaboration policy on innovation output (Figure 6). Government should implement innovation services policy in line with their actual situation based on the in-depth investigation. Practicable innovation services policy can contribute to the costs reduction of innovation collaboration and the enhancement of industryacademia-research cooperation intensity.

\section{Conclusion}

The existing literatures about the NIS have made considerable theoretical progress, but they fail to empirically investigate the time lags of internal transformation process of innovation input-output and the multiple-period influence of one-time innovation input on output based on systems thinking.

In order to explore this new direction of research, firstly, our study has presented an overview of China's NIS based on the conceptual framework and the causal loop diagram. Secondly, we have made use of GCA method measuring the structure and extent of time lags of four major innovation inputs (RRD, RDE, RQ, and UIRC), which represent the four major feedback loops ( $R \& D$ personnel, $R \& D$ expenditure, government's macro-control, and industry-academiaresearch collaboration), respectively, on PAR for China in the period 1996-2012. The distribution of time lags of different innovation input on output varies according to the characteristics, process, and factors. Thirdly, we have provided some policy suggestions taking into account simultaneously shortening the significant time delays which result in accelerating the exponential growth, as well as the side effects of interventions in shortening the delays on dominating negative loops.

On the whole, this study contributes to theory-building and policy-making in the following ways. For theorybuilding, the investigation of time lags properties of the long-run evolution of NIS can complement and inform the NIS research and reveal the long-term complex relationships between the innovation input and output to further understand the operation mechanism of NIS. So it will be an important research direction. For policy-making, identifying the time lags effects of NIS helps policy-makers better understand why an innovation input policy may have no significant effect on innovative performance growth immediately. Therefore, public policy should safeguard the persistence of innovative investment and avoid everything that could disturb the persistent transformation process.

The limitations of our study are particularly interesting and worthy of further exploration in future research. First, NIS is a dynamic system such that its evolution is driven by a complex set of factors. Any given change in one of the factors composing the NIS has a set of direct and indirect effects on the process of transforming innovation input into output. Although this study explicitly analyzes the time lags effects of the four major input-output innovation processes, it is still a simplified structure within which some practical complexities are not taken into account. In our future research, we will attempt to investigate the detailed structure for a better simulation of NIS. Second, this paper 
takes China as an example to investigate the time lags; this could actually be useful for many countries that are in similar transitions from command economy to market economy. But whether our models are appropriate for all other countries needs further verification. Hence, a direction for our future research is to analyze the time lags of more countries by using our hybrid analytical method and to conduct comparative studies between the selected countries.

\section{Competing Interests}

The authors confirm that this paper content has no conflict of interests.

\section{Acknowledgments}

This research is supported by Special Study Project on G20 Innovation Topics, The Ministry of Science and Technology, China; the Fundamental Research Funds 576 for the Central Universities (Grant no. 2572015BX12); and the Educational Science and Planning Project of Heilongjiang Province (Grant no. GJD1214015).

\section{References}

[1] C. Freeman, Technology and Economic Performance: Lessons from Japan, Pinter, London, UK, 1987.

[2] B. Å. Lundvall, Ed., National Innovation Systems: Towards a Theory of Innovation and Interactive Learning, Pinter, London, UK, 1992.

[3] R. Nelson, Ed., National Innovation Systems. A Comparative Analysis, Oxford University Press, New York, NY, USA, 1993.

[4] L. Liu, "Functional approach to innovation systems," Studies in Science of Science, vol. 29, no. 8, pp. 1121-1128, 2011.

[5] F. Castellacci and J. M. Natera, "The dynamics of national innovation systems: a panel cointegration analysis of the coevolution between innovative capability and absorptive capacity," Research Policy, vol. 42, no. 3, pp. 579-594, 2013.

[6] N. Sharif, "Emergence and development of the National Innovation Systems concept," Research Policy, vol. 35, no. 5, pp. 745766, 2006.

[7] J. Niosi, P. Saviotti, B. Bellon, and M. Crow, "National systems of innovation: in search of a workable concept," Technology in Society, vol. 15, no. 2, pp. 207-227, 1993.

[8] A. Filippetti and D. Archibugi, "Innovation in times of crisis: national systems of innovation, structure, and demand," Research Policy, vol. 40, no. 2, pp. 179-192, 2011.

[9] B.-Å. Lundvall, "National innovation systems-analytical concept and development tool," Industry and Innovation, vol. 14, no. 1, pp. 95-119, 2007.

[10] Y. Wang, W. Vanhaverbeke, and N. Roijakkers, "Exploring the impact of open innovation on national systems of innovationa theoretical analysis," Technological Forecasting and Social Change, vol. 79, no. 3, pp. 419-428, 2012.

[11] A. Johnson, "Functions in innovation system approaches," in Proceedings of the Paper for DRUID's Nelson-Winter Conference, Aalborg, Denmark, 2001.

[12] R. Galli and M. Teubal, "Paradigmatic shifts in national innovation systems," in Systems of Innovation: Technologies, Institutions and Organizations, C. Edquist, Ed., Pinter, London, UK, 1997.
[13] A. Bergek, S. Jacobsson, B. Carlsson, S. Lindmark, and A. Rickne, "Analyzing the functional dynamics of technological innovation systems: a scheme of analysis," Research Policy, vol. 37, no. 3, pp. 407-429, 2008.

[14] M. P. Hekkert, R. A. A. Suurs, S. O. Negro, S. Kuhlmann, and R. E. H. M. Smits, "Functions of innovation systems: a new approach for analysing technological change," Technological Forecasting and Social Change, vol. 74, no. 4, pp. 413-432, 2007.

[15] J. Guan and K. Zuo, "A cross-country comparison of innovation efficiency," Scientometrics, vol. 100, no. 2, pp. 541-575, 2014.

[16] M. Kou, K. Chen, S. Wang, and Y. Shao, "Measuring efficiencies of multi-period and multi-division systems associated with DEA: an application to OECD countries' national innovation systems," Expert Systems with Applications, vol. 46, pp. 494-510, 2016.

[17] OECD, OECD Science, Technology and Industry Scoreboard 2015, Organisation for Economic Co-Operation and Development, 2015.

[18] S. Dutta, B. Lanvin, and S. Wunsch-Vincent, Eds., The Global Innovation Index 2015: Effective Innovation Policies for Development, World Intellectual Property Organization, JOHNSON and INSEAD, 2015.

[19] J. P. Li, M. R. Li, and X. L. Zhao, Report on the Group of Twenty(G20) National Innovation Competitiveness Development (2013-2014), Social Sciences Academic Press, Beijing, China, 2014.

[20] Z. Griliches, "Issues in assessing the contribution of research and development to productivity growth," The Bell Journal of Economics, vol. 10, no. 1, pp. 92-116, 1979.

[21] M. Falk, "Quantile estimates of the impact of R\&D intensity on firm performance," Small Business Economics, vol. 39, no. 1, pp. 19-37, 2012.

[22] Y. Sheng, E. M. Gray, and J. D. Mullen, "Public investment in $\mathrm{R} \& \mathrm{D}$ and extension and productivity in Australian broadacre agriculture," in Proceedings of the Australian Agricultural and Resource Economics Society, ABARES Conference Paper 11.08, pp. 9-11, 2011.

[23] S. T. Manzini, "The national system of innovation concept: an ontological review and critique," South African Journal of Science, vol. 108, no. 9-10, 2012.

[24] R. W. Rycroft and D. E. Kash, "Self-organizing innovation networks: implications for globalization," Technovation, vol. 24, no. 3, pp. 187-197, 2004.

[25] R. C. Calia, F. M. Guerrini, and G. L. Moura, "Innovation networks: from technological development to business model reconfiguration," Technovation, vol. 27, no. 8, pp. 426-432, 2007.

[26] K. Smith, "Cross-country comparisons: comparing economic performance in the presence of diversity," Science and Public Policy, vol. 28, no. 4, pp. 267-276, 2001.

[27] B. N. Fan, Z. X. Duan, and L. Jiang, "On independent innovation policy's evolution, effects and optimization in China," Forum on Science and Technology in China, no. 9, pp. 5-12, 2013.

[28] Y. Sun and F. Liu, "A regional perspective on the structural transformation of China's national innovation system since 1999," Technological Forecasting and Social Change, vol. 77, no. 8, pp. 1311-1321, 2010.

[29] M. E. Porter, “The competitive advantage of nations," Harvard Business Review, vol. 68, no. 2, pp. 73-93, 1990.

[30] J. L. Furman, M. E. Porter, and S. Stern, "The determinants of national innovative capacity," Research Policy, vol. 31, no. 6, pp. 899-933, 2002. 
[31] M.-C. Hu and J. A. Mathews, "National innovative capacity in East Asia," Research Policy, vol. 34, no. 9, pp. 1322-1349, 2005.

[32] D. M. You, Z. P. Li, and X. H. Yang, "The influence path of hightech enterprises innovation network capability on innovation network performance," Science of Science and Management of S.e.T, no. 2, pp. 70-82, 2015.

[33] F. C. Liu and T. T. Feng, "A system dynamics model of the formation of national innovative capacity and its applications," Science Research Management, vol. 32, no. 8, pp. 17-25, 2011.

[34] E. Samara, P. Georgiadis, and I. Bakouros, "The impact of innovation policies on the performance of national innovation systems: a system dynamics analysis," Technovation, vol. 32, no. 11, pp. 624-638, 2012.

[35] A.-P. Hameri, “Technology transfer between basic research and industry," Technovation, vol. 16, no. 2, pp. 51-57, 1996.

[36] J. L. Deng, "The grey control system," Journal of Huazhong University of Science and Technology, vol. 3, no. 9, p. 18, 1982.

[37] P. T.-W. Lee, C.-W. Lin, and S.-H. Shin, "A comparative study on financial positions of shipping companies in Taiwan and Korea using entropy and grey relation analysis," Expert Systems with Applications, vol. 39, no. 5, pp. 5649-5657, 2012.

[38] F. Zeng, J. Guo, and C. Long, "A hybrid model of fuzzy logic and grey relation analysis to evaluate tight gas formation quality comprehensively," Journal of Grey System, vol. 27, no. 3, pp. 8798, 2015.

[39] Z. X. Wang, L. L. Pei, and H. B. Ying, “Time-delayed analysis on the driving effect of R\&D investments on the economic growth of China," Statistics \& Information Tribune, vol. 26, no. 12, pp. 49-53, 2012.

[40] L. Liu and B. Guo, "Output lag effect of science and R\&D investment based on grey relational analysis," Science Technology and Industry, vol. 12, no. 10, pp. 81-83, 2012.

[41] D. Wang, X.-L. Zhao, and Z.-S. Zhang, "Study on the lagged effects between national innovation capability and innovation investment within the Group of Twenty based on grey correlation analysis," in Proceedings of the 21th Annual International Conference on Management Science \& Engineering (ICMSE '14), pp. 1593-1599, Helsinki, Finland, August 2014.

[42] D. Kaufmann, A. Kraay, and M. Mastruzzi, "The worldwide governance indicators: methodology and analytical issues," Hague Journal on the Rule of Law, vol. 3, no. 2, pp. 220-246, 2011.

[43] Z. Griliches, "Patent statistics as economic indicators: a survey," Journal of Economic Literature, vol. 28, no. 4, pp. 1661-1707, 1990.

[44] N. Wang and J. Hagedoorn, "The lag structure of the relationship between patenting and internal R\&D revisited," Research Policy, vol. 43, no. 8, pp. 1275-1285, 2014.

[45] E. Fé and R. Hofler, "Count data stochastic frontier models, with an application to the patents-R\&D relationship," Journal of Productivity Analysis, vol. 39, no. 3, pp. 271-284, 2013.

[46] F. C. Liu and T. T. Feng, "A system dynamic model of the formation of national innovative capacity-regarding invention patent as token element of capacity," Management Review, vol. 23, no. 5, pp. 30-38, 2011.

[47] D. A. Dickey and W. A. Fuller, "Distribution of the estimators for autoregressive time series with a unit root," Journal of the American Statistical Association, vol. 74, no. 366, pp. 427-431, 1979.

[48] H.-S. Jung and E. Thorbecke, "The impact of public education expenditure on human capital, growth, and poverty in Tanzania and Zambia: a general equilibrium approach," Journal of Policy Modeling, vol. 25, no. 8, pp. 701-725, 2003.
[49] G. Szulanski, "The process of knowledge transfer: a diachronic analysis of stickiness," Organizational Behavior and Human Decision Processes, vol. 82, no. 1, pp. 9-27, 2000.

[50] I. Nonaka and H. Takeuchi, The Knowledge Creating Company: How Japanese Companies Create the Dynamics of Innovation, Oxford University Press, New York, NY, USA, 1995.

[51] H. C. Cristian, "Knowledge transfer opportunities for the bioscience sector in Chile," Journal of Technology Management \& Innovation, vol. 1, no. 3, pp. 4-16, 2006.

[52] T. Barnes, I. Pashby, and A. Gibbons, "Effective universityindustry interaction: a multi-case evaluation of collaborative R\&D projects," European Management Journal, vol. 20, no. 3, pp. 272-285, 2002.

[53] S. Rast, A. Tourani, and A. S. Aslan, "Effect of organizational factors on university-industry collaboration: a conceptual model," International Journal of Business and Management, vol. 10, no. 6, 2015.

[54] Y. Kodcharat and A. Chaikeaw, "University and industrial sector collaboration: the key factors affecting knowledge transfer," International Journal of Business and Social Science, vol. 3, no. 23, pp. 130-137, 2012. 


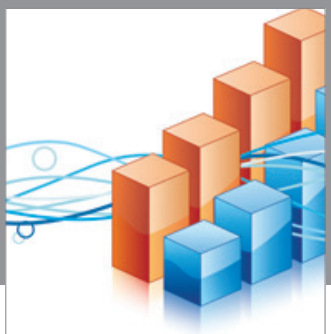

Advances in

Operations Research

vatem alat4

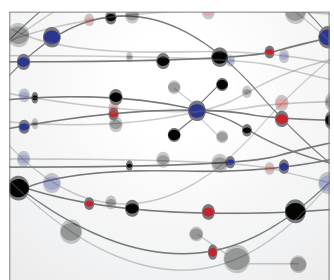

\section{The Scientific} World Journal
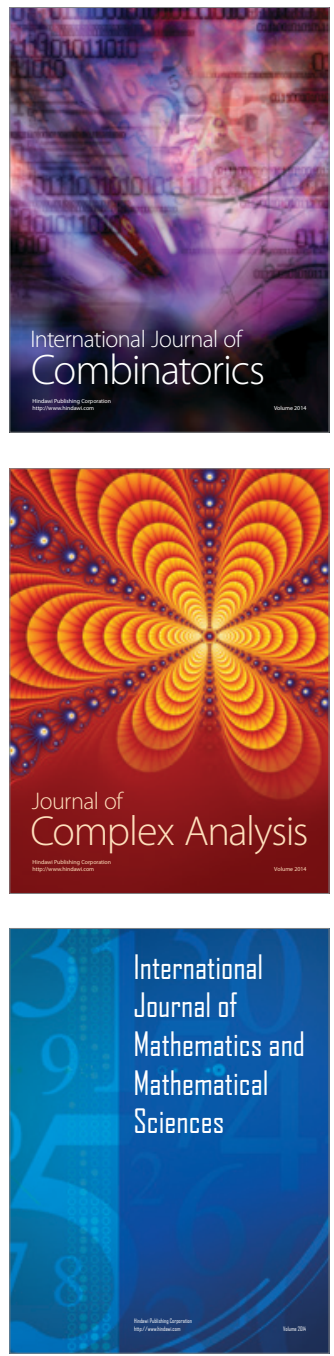
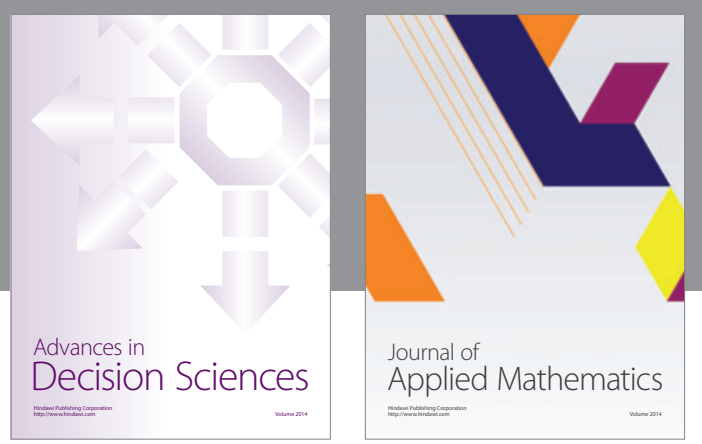

Algebra

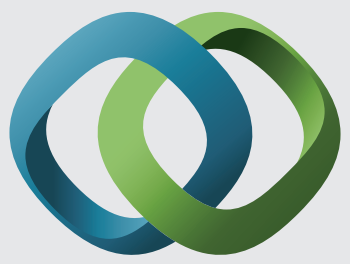

\section{Hindawi}

Submit your manuscripts at

http://www.hindawi.com
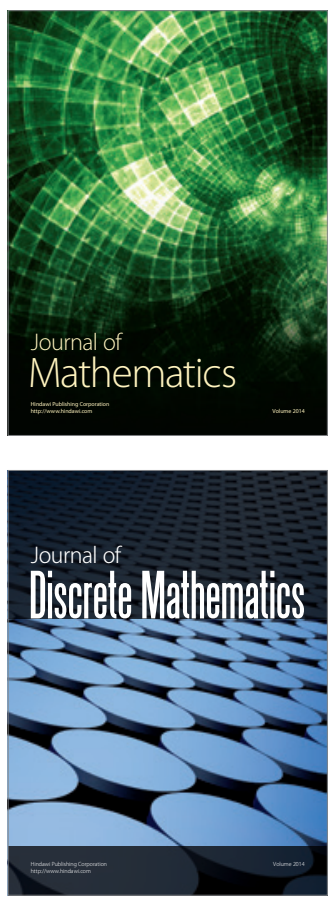

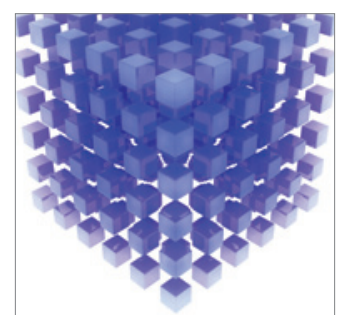

Mathematical Problems in Engineering
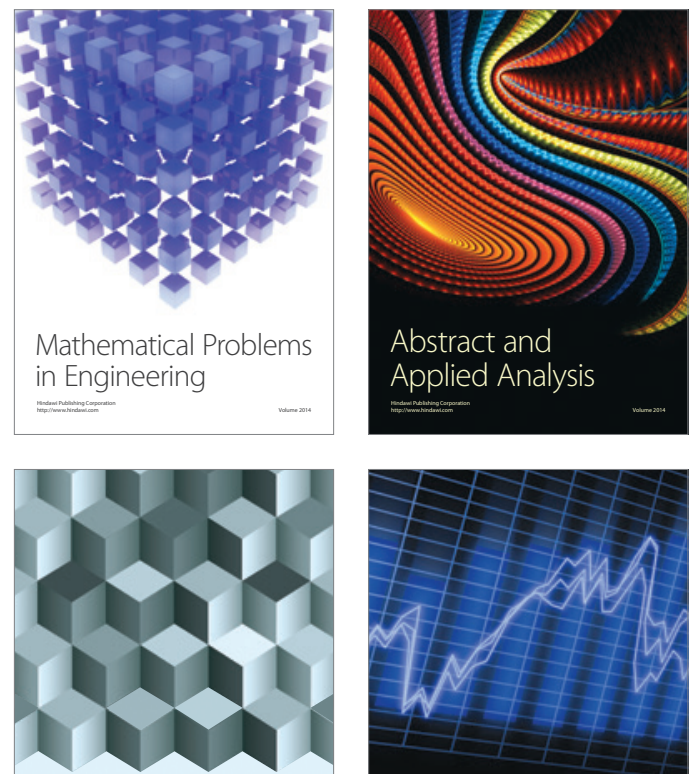

Journal of

Function Spaces

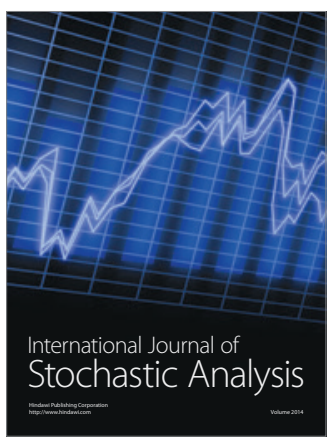

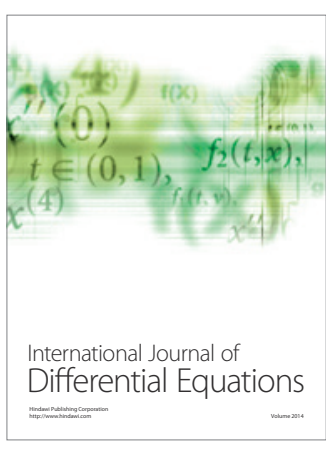
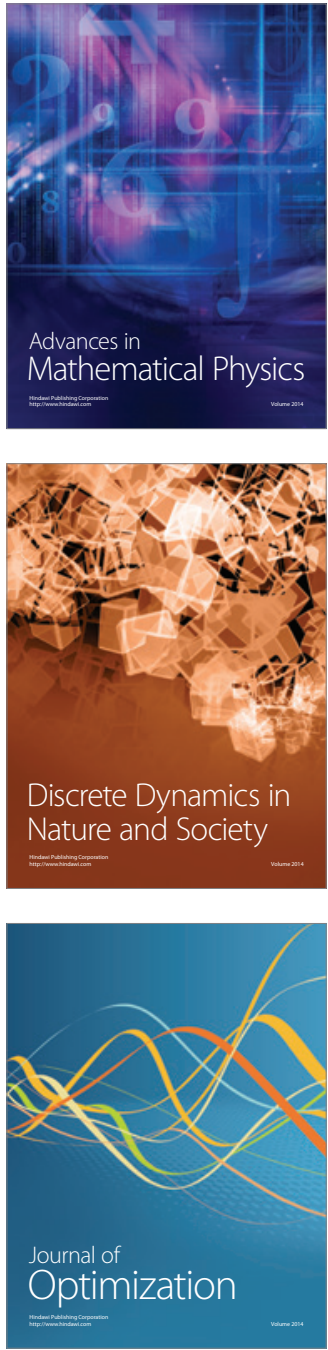